\title{
A New Approach to the Identification of Distillation Column Based on Hammerstein Model
}

\author{
Ramesh Kanthasamy, ${ }^{1}$ Hisyam Anwaruddin, ${ }^{1}$ and Suriya Kumar Sinnadurai ${ }^{2}$ \\ ${ }^{1}$ Process Systems Engineering Group (PSEG), Faculty of Chemical \& Natural Resources Engineering, Universiti Malaysia Pahang, \\ 26300 Kuantan, Pahang, Malaysia \\ ${ }^{2}$ Centre for Modern Languages and Human Sciences, Universiti Malaysia Pahang, 26300 Kuantan, Pahang, Malaysia
}

Correspondence should be addressed to Ramesh Kanthasamy; ramesh@ump.edu.my

Received 31 July 2013; Revised 11 December 2013; Accepted 11 December 2013; Published 18 February 2014

Academic Editor: Abdelali El Aroudi

Copyright (C) 2014 Ramesh Kanthasamy et al. This is an open access article distributed under the Creative Commons Attribution License, which permits unrestricted use, distribution, and reproduction in any medium, provided the original work is properly cited.

Developing a suitable nonlinear model is the most challenging problem in the application of nonlinear model based controllers to distillation column. Hammerstein model consists of a nonlinear static element described by wavenet based nonlinear function, followed by a linear dynamic element described by the Output Error(OE) model was used in this study to represent the nonlinear dynamics of the distillation column. The model parameters were identified using iterative prediction-error minimization method. The model validation results proved that the Hammerstein model was capable of capturing the nonlinear dynamics of distillation column.

\section{Introduction}

Distillation is a complex multivariable system and exhibits highly nonlinear dynamic behavior due to its nonlinear vapor-liquid equilibrium relationships. In most chemical processes, understanding the nonlinear characteristics is important for designing controllers that regulate the process [1]. Unlike linear systems, each nonlinear system exhibits different nonlinear characteristics and therefore there are no unique nonlinear functions to describe them. Most physical devices have nonlinear characteristics outside a limited linear range. Many authors [2, 3] have noted the difficulty of developing the models required for nonlinear model-based control strategies. With carefully designed data collection experiments, the dominant behavior of plant can be fitted into one of the several possible structures. The main challenge in this task is to select a reasonable structure for the nonlinear model to capture the process nonlinearities. The nonlinear model used in control purposes should be as simple as possible, warranting less computational load and at the same time retaining most of the nonlinear dynamic characteristics of the system.

Many model structures have been proposed for the identification of distillation column such as NARX model [4, 5], Hammerstein model [6], and Weiner model [7]. The nonlinear static block followed by a linear dynamic block in the Hammerstein model has been considered as alternative to linear models in a number of chemical process applications such as distillation columns [6], heat exchangers [1], and CSTR [8].

The classical structure of the Hammerstein model is shown in Figure 1, where $u(k)$ is an input and $x(k)$ is an output of the nonlinear static block. Simultaneously $x(k)$ is an input and $y(k)$ is an output of the linear dynamic block. Eskinat et al. [1] compared Hammerstein models to linear models for approximating the dynamics of a distillation column and a heat exchanger. Low-order polynomials were assumed for the nonlinearity. For the distillation column example, it was shown that the Hammerstein model provided a reasonable approximation to the column dynamics, provided 


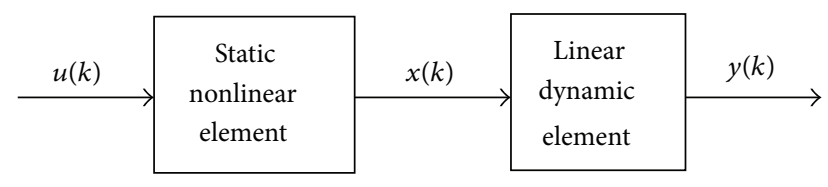

FIGURE 1: Hammerstein model structure.

the required product purity was not too high. The resulting polynomial approximations are generally nonmonotonic, implying that the identified Hammerstein model can exhibit input multiplicities that are not representative of the true process.

Fruzzetti et al. [9] have proposed a nonlinear model using the Hammerstein model structure to control a binary distillation column. They modeled the nonlinear static portion of the system by a power series and linear dynamic function by a linear transfer function model. They used forward-regression orthogonal estimator for model identification and claimed that the identification algorithm has the ability to determine the model structure as well as the model parameters and provide information about model inaccuracy. The main drawback of their model is that the manipulated variables, reflux flow rate and vapor boil up rate, should remain within $\pm 10 \%$ of their steady-state values. So when the model is used for control purposes it cannot give accurate results for large disturbances and large set point changes. Nugroho et al. [10] have studied the nonlinear identification of aqueous ammonia binary distillation column based on Hammerstein model. They employed simple quadratic function to represent the nonlinear static portion of the system and linear transfer function model to represent the linear dynamic function.

Different techniques have been proposed for the estimation of Hammerstein systems from input-output measurements. These techniques mainly differ in the way that static nonlinearity is represented and also based on the type of optimization problem that is finally obtained. The Narendra and Gallman (1966) proposed an iterative algorithm which is referred as Narendra Gallman Algorithm (NGA) rovided the initial momentum to block oriented modeling. This algorithm updates the linear dynamic element and the nonlinear gain polynomial separately and sequentially. The NGA provides accurate parameter estimation and is actually faster for higher order systems. Eskinat et al. [1] established the robustness of NGA to various levels of noise. Also they compared the NGA with other well-known identification methods such as prediction error method (PEM) and the recursive prediction error method (RPEM). They concluded that NGA and PEM are giving almost similar results for all types of noise levels whereas RPEM is not suitable for all types of conditions. Lakshminarayanan et al. [12] have presented the identification of Hammerstein models using multivariate statistical tools. They obtained the parameters of linear system in state space form using canonical correlation analysis and adjusted the coefficients of the polynomial type nonlinear elements until convergence occurs.

Al-Duwaish and Karim [13] have developed the recursive algorithm for the identification of Hammerstein model and in their model the static nonlinear part is modeled by a

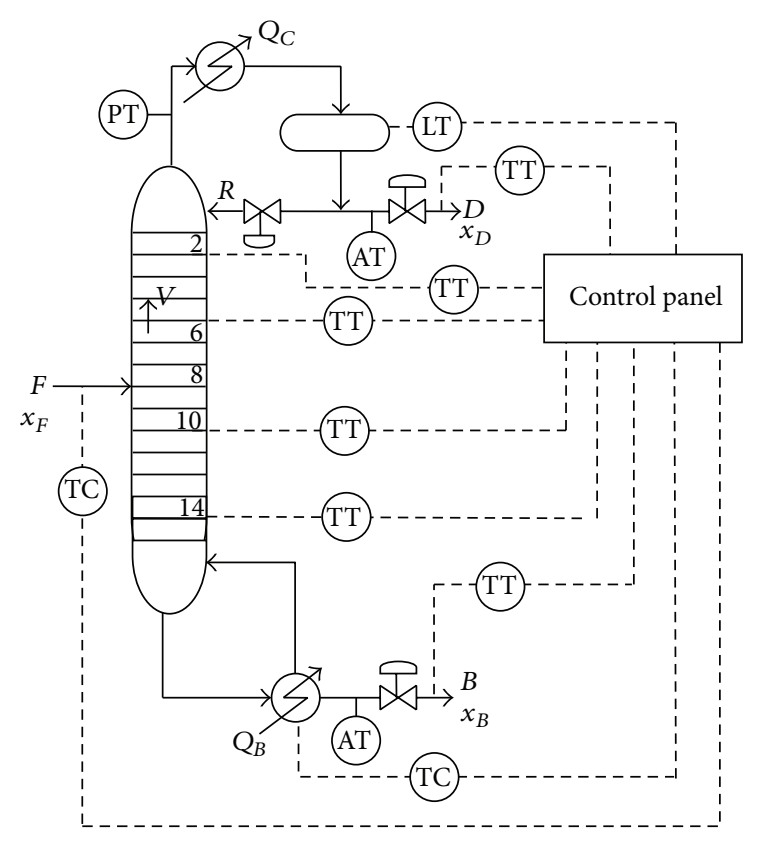

FIGURE 2: Pilot plant distillation column.

multilayer feedforward neural network (MFNN) and the linear part is modeled by an autoregressive moving average (ARMA) model. Bai [14] reported a two-stage identification algorithm based on the recursive least-squares and on the singular value decomposition and a blind identification approach [15] to the Hammerstein model. Two identification algorithms, an iterative least-squares and a recursive leastsquares, are developed for Hammerstein nonlinear systems with memoryless nonlinear blocks and linear dynamical blocks described by ARMAX/CARMA models [16]. Biagiola and Figueroa proposed the noniterative algorithms for the robust identification of Wiener and Hammerstein uncertain models for SISO system using various simulation examples [17] and for MIMO system using distillation column case study [18]. Two multiple-input single-output (MISO) Hammerstein models are developed in this work to model the dynamics of the distillation column. In both the MISO models used this work, wavenet function is used as static nonlinear element and output error (OE) model is used as linear dynamic element.

\section{Distillation Column}

The schematic of pilot plant distillation column utilized in this study is shown in Figure 2. The methanol-water binary mixture was used as the feed material. The top and bottom product compositions were the controlled variables in the distillation column. The reflux flow rate and reboiler vapor boil-up rate were used as the manipulated variables, whereas feed flow rate and feed composition were considered as the disturbances. The nominal operating conditions and the column parameters are listed in Table 1. The reboiler and feed temperatures were controlled using separate PID controllers. In all the experiments, tray 2 , tray 6 , tray 10 , tray 14 , and 
TABLE 1: Nominal operating conditions and the column parameters.

\begin{tabular}{lc}
\hline Number of trays & 15 \\
Feed tray number & 8 \\
Column diameter & $10.8 \mathrm{~cm}$ \\
Weir height & $2 \mathrm{~cm}$ \\
Weir length & $8.3 \mathrm{~cm}$ \\
Feed composition & 0.308 \\
Feed flow rate & $1 \mathrm{kmol} / \mathrm{h}$ \\
Distillate composition & 0.98 \\
Distillate flow rate & $0.31 \mathrm{kmol} / \mathrm{h}$ \\
Bottoms flow rate & $0.69 \mathrm{kmol} / \mathrm{h}$ \\
Reflux flow rate & $1.09 \mathrm{kmol} / \mathrm{h}$ \\
Reflux drum holdup & $0.015 \mathrm{~m}$ \\
Reboiler holdup & $0.007 \mathrm{~m}$ \\
Mol. weight of methanol & $32 \mathrm{~kg} / \mathrm{kmol}$ \\
Mol. weight of water & $18 \mathrm{~kg} / \mathrm{kmol}$ \\
\hline
\end{tabular}

distillate and bottom products temperatures were measured. The top and bottom product compositions were determined using refractive index analysis.

In this work, the well-known first principle model was used as the process model to generate data required for the nonlinear identification. In the first principle model, the equations for the Material balance, the Equilibrium phase, the Summation, and the Heat balance for each stage (so-called MESH equations) were solved in order to provide the product distributions, flow rates, and temperatures. The Francis weir formula was used to calculate the liquid holdup and liquid flow rate in each tray.

The calculation of activity and fugacity coefficients were included in order to account for the nonideality. The activity coefficients are calculated using UNIFAC model [19] and the fugacity coefficients were calculated using virial equation of state [19]. The detailed equilibrium model equations are given by Ramesh et al. [20].

The steady-state and dynamic experimental studies on pilot plant distillation column were conducted to validate the first principle model. Initially the tray efficiency used in the first principle model was assumed to be $45 \%$ for all trays. Subsequently, the tray efficiency values were calibrated by trial and error method using the steady-state experimental results. Calibrated tray efficiencies were varied from $32 \%$ to $35.7 \%$ between tray 1 and tray 15 and those values were used throughout the simulation studies.

Table 2 shows the comparison of experimental steadystate data with the simulation results. The steady-state experimental results showed that the model values are in accordance with the experimental results with error below $4.5 \%$. This could be due to the proper calibration of the tray efficiencies used in the mathematical model.

The experimental and simulated responses in top product composition for positive $(+10 \%)$ step change in reflux flow rate were compared in Figure 3, and it has been observed that the experiment and model results were in reasonable agreement. The comparison between experimental and simulated responses in bottom product composition for positive
TABLE 2: Comparison between steady-state experimental and simulation results.

\begin{tabular}{lccc}
\hline Parameters & Experimental & Simulation & \% error \\
\hline$x_{D}$ & 0.889 & 0.907 & 2.03 \\
$x_{B}$ & 0.153 & 0.1465 & 4.44 \\
Tray 2 Temp. & $90^{\circ} \mathrm{C}$ & $89.83^{\circ} \mathrm{C}$ & 0.19 \\
Tray 6 Temp. & $84^{\circ} \mathrm{C}$ & $83.87^{\circ} \mathrm{C}$ & 0.16 \\
Tray 10 Temp. & $74^{\circ} \mathrm{C}$ & $73.83^{\circ} \mathrm{C}$ & 0.23 \\
Tray 14 Temp. & $68^{\circ} \mathrm{C}$ & $68.71^{\circ} \mathrm{C}$ & 1.03 \\
\hline
\end{tabular}

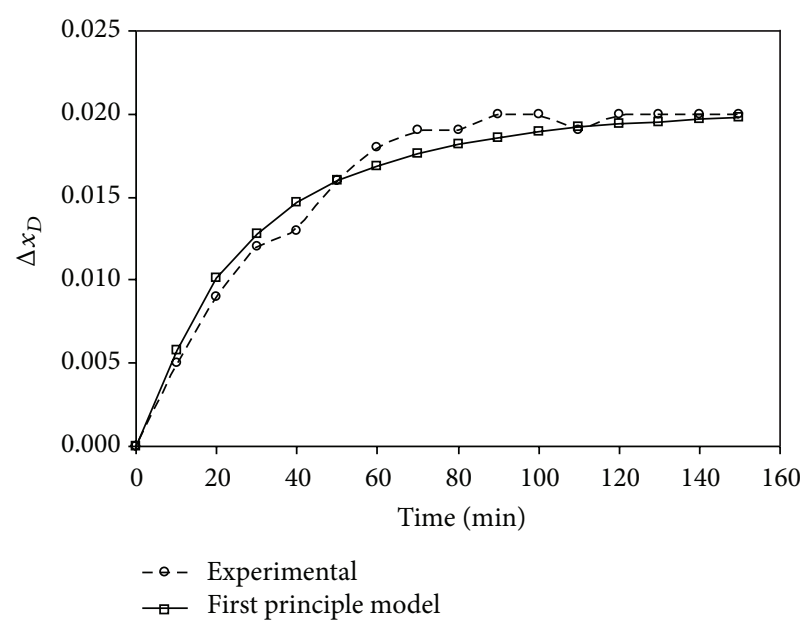

FIgURE 3: Comparison between experimental and simulated responses in top product composition for positive step change in reflux flow rate.

step change in reflux flow rate was shown in Figure 4 where a high level of consistency has been observed between the model and experimental results. The steady-state and dynamic experimental studies in the pilot plant distillation column showed good agreement between the first principle model and the experimental results. The experimentally validated first principle model was used as process model in Hammerstein model parameter estimation and validation. The nonlinearity of the distillation column used in this study was already proved in [20].

\section{Wavenet Based Hammerstein Model}

Two multiple-input single-output (MISO) Hammerstein models are developed in this work to model the dynamics of the distillation column. The reason for using two MISO models instead of multiple-input multiple-output (MIMO) model is that the MISO models provide better prediction compared to MIMO model [1]. The first MISO model uses reflux flow rate $(L)$ and reboiler heat load $\left(Q_{R}\right)$ as inputs and top product composition $\left(x_{D}\right)$ as output, while the second MISO model uses reflux flow rate $(L)$ and reboiler heat load $\left(Q_{R}\right)$ as inputs and bottom product composition $\left(x_{B}\right)$ as output. The MISO Hammerstein models are more complicated than MISO linear models. The MISO case can give rise to two model structures depending on whether 


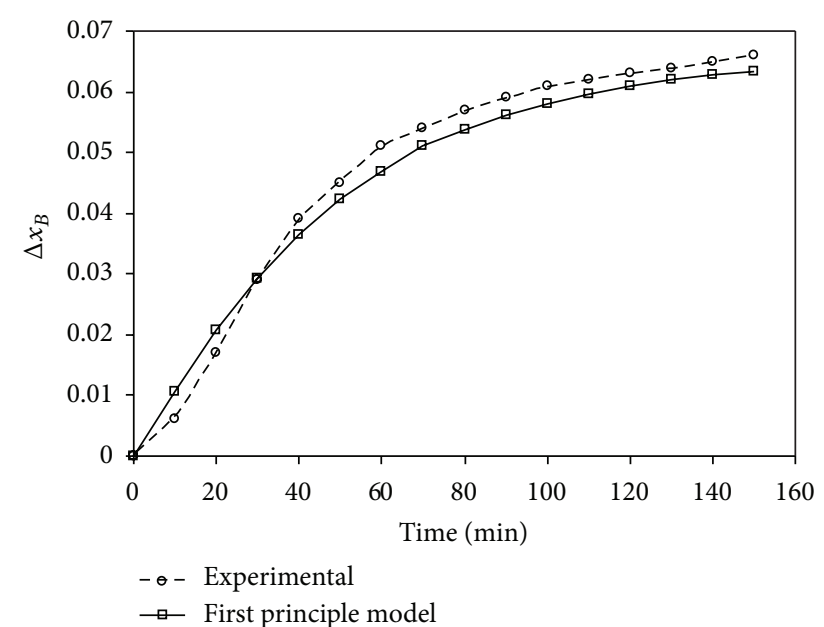

FIgURE 4: Comparison between experimental and simulated responses in bottom product composition for positive step change in reflux flow rate.

the static nonlinearity is combined or separated. The combined nonlinearity case is more general, but it can cause a very challenging problem because of the large number of parameters to be estimated. In this study, the separately parameterized nonlinearity structured Hammerstein model was used. In both the MISO models used in this work, wavenet function with 2 units is used as static nonlinear element and OE model with $n a=2, n b=1$, and $n k=1$ is used as linear dynamic element for both inputs $u_{1}$ and $u_{2}$.

3.1. Model Structure. The linear block is the output error $(\mathrm{OE})$ model [19] which is given by (1a)-(1e). Consider

$$
y(k)=\frac{B_{1}\left(q^{-1}\right)}{A_{1}\left(q^{-1}\right)} x_{1}(k)+\frac{B_{2}\left(q^{-1}\right)}{A_{2}\left(q^{-1}\right)} x_{2}(k) .
$$

The polynomials $B_{1}\left(q^{-1}\right), A_{1}\left(q^{-1}\right), B_{2}\left(q^{-1}\right)$, and $A_{2}\left(q^{-1}\right)$ in (1a)-(1e) are defined as

$$
\begin{gathered}
B_{1}\left(q^{-1}\right)=b_{11} q^{-n k}+b_{21} q^{-(n k+1)}+\cdots+b_{n b 1} q^{-(n k+n b+1)}, \\
A_{1}\left(q^{-1}\right)=1+a_{11} q^{-1}+a_{21} q^{-2}+\cdots+a_{n a 1} q^{-n a}, \\
B_{2}\left(q^{-1}\right)=b_{12} q^{-n k}+b_{22} q^{-(n k+1)}+\cdots+b_{n b 2} q^{-(n k+n b+1)}, \\
A_{2}\left(q^{-1}\right)=1+a_{12} q^{-1}+a_{22} q^{-2}+\cdots+a_{n a 2} q^{-n a} .
\end{gathered}
$$

Wavenet structure based nonlinear function $x=F(u)$ is used to represent the static nonlinearity of the Hammerstein model [19]:

$$
\begin{aligned}
x_{1}(k)= & F\left(u_{1}\right) \\
= & \left(u_{1}-r_{1}\right) P_{1} L_{1}+a s_{11} f\left(b s_{11}\left(\left(u_{1}-r_{1}\right) Q_{1} c s_{11}\right)\right) \\
& +\cdots+a s_{k 1} f\left(b s_{k 1}\left(\left(u_{1}-r_{1}\right) Q_{1} c s_{k 1}\right)\right) \\
& +a w_{11} g\left(b w_{11}\left(\left(u_{1}-r_{1}\right) Q_{1}-c w_{11}\right)\right) \\
& +\cdots+a w_{k 1} g\left(b w_{k 1}\left(\left(u_{1}-r_{1}\right) Q_{1}-c w_{k 1}\right)\right)+d_{1}, \\
x_{2}(k)= & F\left(u_{2}\right) \\
= & \left(u_{2}-r_{2}\right) P_{2} L_{2}+a s_{12} f\left(b s_{12}\left(\left(u_{2}-r_{2}\right) Q_{2} c s_{12}\right)\right) \\
& +\cdots+a s_{k 2} f\left(b s_{k 2}\left(\left(u_{2}-r_{2}\right) Q_{2} c s_{k 2}\right)\right) \\
& +a w_{12} g\left(b w_{12}\left(\left(u_{2}-r_{2}\right) Q_{2}-c w_{12}\right)\right) \\
& +\cdots+a w_{k 2} g\left(b w_{k 2}\left(\left(u_{2}-r_{2}\right) Q_{2}-c w_{k 2}\right)\right)+d_{2} .
\end{aligned}
$$

Substituting (5) and (6) in to (1a)-(1e), the output of the wavenet based Hammerstein model $y(k)$ is given by

$$
\begin{aligned}
y(k)= & \frac{B_{1}\left(q^{-1}\right)}{A_{1}\left(q^{-1}\right)} F\left(u_{1}\right) \\
= & \left(u_{1}-r_{1}\right) P_{1} L_{1}+a s_{11} f\left(b s_{11}\left(\left(u_{1}-r_{1}\right) Q_{1} c s_{11}\right)\right) \\
& +\cdots+a s_{k 1} f\left(b s_{k 1}\left(\left(u_{1}-r_{1}\right) Q_{1} c s_{k 1}\right)\right) \\
& +a w_{11} g\left(b w_{11}\left(\left(u_{1}-r_{1}\right) Q_{1}-c w_{11}\right)\right) \\
& +\cdots+a w_{k 1} g\left(b w_{k 1}\left(\left(u_{1}-r_{1}\right) Q_{1}-c w_{k 1}\right)\right)+d_{1} \\
& +\frac{B_{2}\left(q^{-1}\right)}{A_{2}\left(q^{-1}\right)}\left(u_{2}-r_{2}\right) P_{2} L_{2} \\
& +a s_{12} f\left(b s_{12}\left(\left(u_{2}-r_{2}\right) Q_{2} c s_{12}\right)\right) \\
& +\cdots+a s_{k 2} f\left(b s_{k 2}\left(\left(u_{2}-r_{2}\right) Q_{2} c s_{k 2}\right)\right) \\
& +a w_{12} g\left(b w_{12}\left(\left(u_{2}-r_{2}\right) Q_{2}-c w_{12}\right)\right) \\
& +\cdots+a w_{k 2} g\left(b w_{k 2}\left(\left(u_{2}-r_{2}\right) Q_{2}-c w_{k 2}\right)\right)+d_{2} .
\end{aligned}
$$

The scaling functions $f\left(u_{1}\right)$ and $f\left(u_{2}\right)$ in $(2)$ are given by

$$
\begin{aligned}
& f\left(u_{1}\right)=\exp \left(-0.5 u_{1}^{\prime} u_{1}\right), \\
& f\left(u_{2}\right)=\exp \left(-0.5 u_{2}^{\prime} u_{2}\right) .
\end{aligned}
$$

The wavelet functions $g\left(u_{1}\right)$ and $g\left(u_{2}\right)$ in (2) are given by

$$
\begin{aligned}
& g\left(u_{1}\right)=\left(\operatorname{dim}\left(u_{1}\right)-u_{1}^{\prime} u_{1}\right) \exp \left(-0.5 u_{1}^{\prime} u_{1}\right), \\
& g\left(u_{2}\right)=\left(\operatorname{dim}\left(u_{2}\right)-u_{2}^{\prime} u_{2}\right) \exp \left(-0.5 u_{2}^{\prime} u_{2}\right) .
\end{aligned}
$$


TABLE 3: Parameters of MISO Hammerstein models.

\begin{tabular}{ll}
\hline First MISO model & Second MISO model \\
\hline$a_{11}=-1.334, a_{21}=0.36$ & $a_{11}=-1.338, a_{21}=0.3498$ \\
$a_{12}=-1.316, a_{22}=0.3406$ & $a_{12}=-1.092, a_{22}=0.109$ \\
$b_{11}=1, b_{12}=1$ & $b_{11}=1, b_{12}=1$ \\
$P_{1}=55.13$ & $P_{1}=55.13$ \\
$P_{2}=2.991$ & $P_{2}=2.984$ \\
$Q_{1}=55.13$ & $Q_{1}=55.13$ \\
$Q_{2}=2.991$ & $Q_{2}=2.984$ \\
$L_{1}=1.385 \times 10^{-4}$ & $L_{1}=2.804 \times 10^{-4}$ \\
$L_{2}=-1.438 \times 10^{-4}$ & $L_{2}=-5.015 \times 10^{-4}$ \\
$d_{1}=-2.61 \times 10^{-4}$ & $d_{1}=-5.21 \times 10^{-4}$ \\
$d_{2}=2.45 \times 10^{-4}$ & $d_{2}=7.37 \times 10^{-4}$ \\
$r_{1}=4.02 \times 10^{-4}$ & $r_{1}=4.13 \times 10^{-4}$ \\
$r_{2}=-0.0046$ & $r_{2}=-0.0044$ \\
$a w_{11}=-0.017 \times 10^{-4}$ & $a w_{11}=-9.45 \times 10^{-6}$ \\
$a w_{12}=-0.209 \times 10^{-4}$ & $a w_{12}=-7.48 \times 10^{-5}$ \\
$b w_{11}=15.99$ & $b w_{11}=15.53$ \\
$b w_{12}=15.803$ & $b w_{12}=15.98$ \\
$c w_{11}=-2.024$ & $c w_{11}=-0.5621$ \\
$c w_{12}=1$ & $c w_{12}=1$ \\
$a s_{11}=0$ & $a s_{11}=-4.33 \times 10^{-5}$ \\
$a s_{12}=-1.75 \times 10^{-5}$ & $a s_{12}=6.04 \times 10^{-5}$ \\
$b s_{11}=0.005$ & $b s_{11}=31.104$ \\
$b s_{12}=16.01$ & $b s_{12}=16.002$ \\
$c s_{11}=-0.014$ & $c s_{11}=0.8469$ \\
$c s_{12}=1$ & $c s_{12}=1$ \\
\hline &
\end{tabular}

3.2. Parameter Estimation. The models considered here ultimately require the estimation of unknown model parameters from input/output data. The ident function in system identification toolbox version 7.0 in MATLAB was employed for parameter estimation. The model parameters were estimated using iterative prediction-error minimization method [21]. The error criterion is formed and the model parameters are obtained by minimizing the error criterion by iterative method. The minimization involves the calculation of Hessian and gradient of the error criterion. Gradient is calculated from the derivatives. However, Hessian is difficult to compute; hence, Levenberg-Marquardt method is used to approximate the Hessian of the quadratic criterion.

The parameters of MISO Hammerstein models were estimated using the data generated from the process model. The input data $u_{1}(k)$ which is generated using random Gaussian signal to reflux flow rate $(L)$ and $u_{2}(k)$ which is generated using random Gaussian signal to reboiler heat load $\left(Q_{B}\right)$ were used in model parameter estimation. The parameters of each MISO model were estimated separately and the values are given in Table 3.

3.3. Model Validation. The validation of wavenet based MISO Hammerstein models was carried out using different datasets that were not used in parameter estimation. The comparison

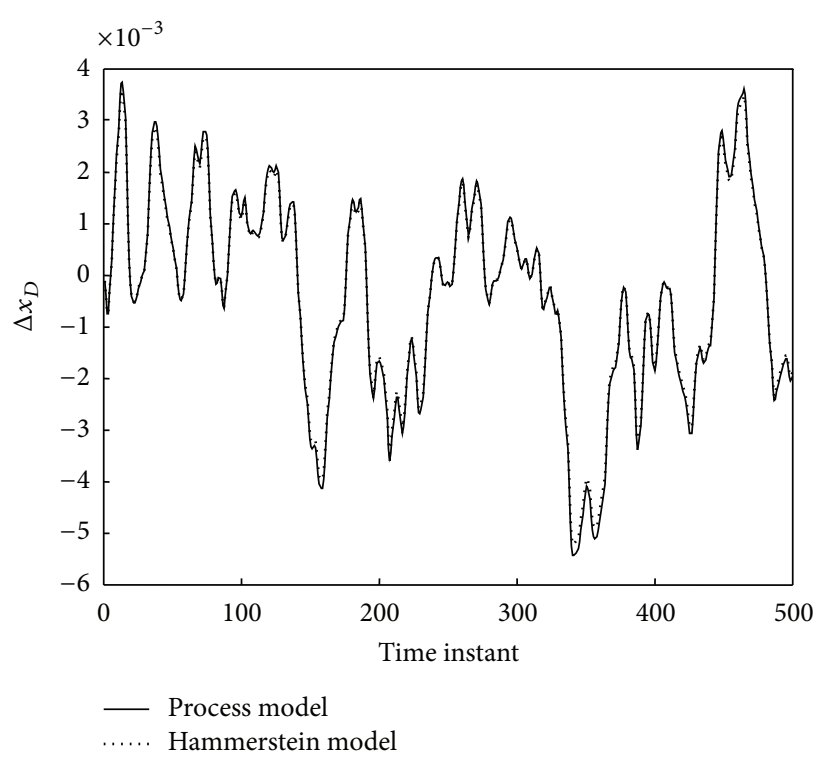

FIGURE 5: Comparison between the responses of first MISO Hammerstein model and process model.

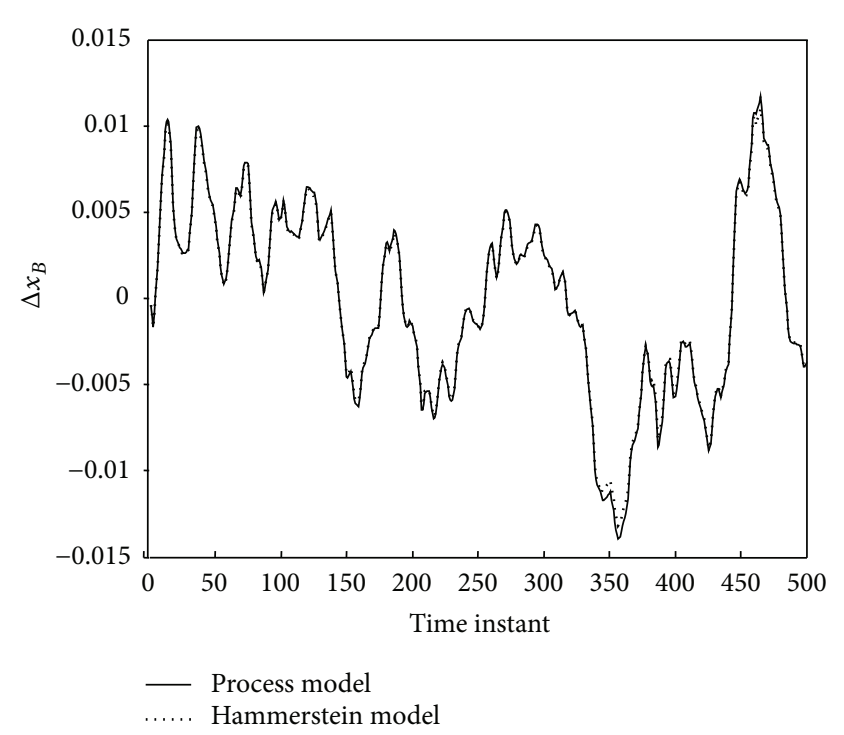

FIGURE 6: Comparison between the responses of second MISO Hammerstein model and process model.

between the first MISO Hammerstein model output and corresponding process model output is shown in Figure 5. It has been observed that the Hammerstein model results showed 94.64\% agreement with the process model results based on adjusted $R^{2}$ value. The comparison between the second MISO Hammerstein model output and the corresponding process model output which is bottom product composition was shown in Figure 6. It has been noted that the second MISO Hammerstein model results are $95.12 \%$ in agreement with the process model results based on adjusted $R^{2}$ value. The validation results proved that the wavenet based nonlinear 
static element present in the MISO models has the ability to capture the nonlinear dynamics of the process.

\section{Conclusion}

A new wavenet based Hammerstein model was developed to capture the nonlinear dynamics of the distillation column. The data generated from experimentally validated first principle model was used for parameter estimation and model validation. The model parameters were estimated using iterative prediction-error minimization method. The model validation results have shown that the new wavenet based Hammerstein model has good agreement with the process model.

\section{Nomenclature}

\begin{tabular}{|c|c|}
\hline$a_{n a 1}:$ & Coefficients of polynomial $A_{1}$ \\
\hline$a_{n a 2}:$ & Coefficients of polynomial $A_{2}$ \\
\hline$a s_{k}:$ & Scaling coefficient \\
\hline AT: & Analysis transmitter \\
\hline$a w_{k}:$ & Wavelet coefficient \\
\hline$b_{n b 1}:$ & Coefficients of polynomial $B_{1}$ \\
\hline$b_{n b 2}:$ & Coefficients of polynomial $B_{2}$ \\
\hline$b s_{k}:$ & Scaling dilation coefficient \\
\hline$b w_{k}:$ & Wavelet dilation coefficient \\
\hline$B:$ & Bottom product flow rate $(\mathrm{kmol} / \mathrm{h})$ \\
\hline$c s_{k}:$ & Scaling translation coefficient \\
\hline$c w_{k}:$ & Wavelet translation coefficient \\
\hline$D:$ & Distillate flow rate $(\mathrm{kmol} / \mathrm{h})$ \\
\hline$d:$ & Output offset \\
\hline$f(u):$ & Scaling function \\
\hline$F:$ & Feed flow rate $(\mathrm{kmol} / \mathrm{h})$ \\
\hline$g(u):$ & Wavelet function \\
\hline LC: & Level controller \\
\hline na: & Number of past outputs \\
\hline$n b:$ & Number of past inputs \\
\hline$n k$ : & Delay from input to the output \\
\hline$P:$ & Nonlinear subspace parameter \\
\hline PT: & Pressure transmitter \\
\hline$Q_{B}:$ & Reboiler heat load (kW) \\
\hline$Q_{C}:$ & Heat removed from condenser $(\mathrm{kW})$ \\
\hline Q: & Linear subspace parameter \\
\hline$L:$ & Reflux flow rate $(1 / \mathrm{min})$ \\
\hline $\mathrm{L}:$ & $\begin{array}{l}\text { Linear term coefficient in wavenet function } \\
\text { (Note: } L \text { is used to represent reflux flow rate } \\
\text { and also Linear term coefficient in wavenet } \\
\text { function) }\end{array}$ \\
\hline$r:$ & Regressor mean \\
\hline TC: & Temperature controller \\
\hline TT: & Temperature transmitter \\
\hline$u(k):$ & Input to the Hammerstein model \\
\hline VB: & Vapor boilup rate $(\mathrm{kmol} / \mathrm{h})$ \\
\hline$x_{B}:$ & Bottom product composition \\
\hline$x_{D}:$ & Top product composition \\
\hline$x_{F}:$ & Feed composition \\
\hline
\end{tabular}

\section{Conflict of Interests}

The authors declare that there is no conflict of interests related to this paper.

\section{References}

[1] E. Eskinat, S. H. Johnson, and W. L. Luyben, "Use of Hammerstein models in identification of nonlinear systems," AIChE Journal, vol. 37, no. 2, pp. 255-268, 1991.

[2] R. K. Pearson, "Selecting nonlinear model structures for computer control," Journal of Process Control, vol. 13, no. 1, pp. 1-26, 2003.

[3] S. Qin and T. Badgewell, "An overview of nonlinear predictive control applications," in Proceedings of the International symposium on Nonlinear Model Predictive Control: Assessment and Future Directions, pp. 128-145, Ascona, Switzerland, 1998.

[4] K. Rarnesh, S. R. Abd Shukor, and N. Aziz, "Nonlinear model predictive control of a distillation column using NARX model," Computer Aided Chemical Engineering, vol. 27, no. C, pp. 15751580, 2009.

[5] K. Ramesh, S. R. A. Shukor, and N. Aziz, "Development of sigmoidnet based NARX model for a distillation column," Chemical Product and Process Modeling, vol. 3, no. 2, article 4, 2008.

[6] K. Ramesh, A. Hisyam, N. Aziz, and S. R. Abd Shukor, "Nonlinear model predictive control of a distillation column using Wavenet Based Hammerstein model," Engineering Letters, vol. 20, no. 4, article 330, 2012.

[7] S. J. Norquay, A. Palazoglu, and J. A. Romagnoli, "Application of Wiener model predictive control (WMPC) to an industrial C2-splitter," Journal of Process Control, vol. 9, no. 6, pp. 461-473, 1999.

[8] M. Pottmann and R. K. Pearson, "Block-oriented NARMAX models with output multiplicities," AIChE Journal, vol. 44, no. 1, pp. 131-140, 1998.

[9] K. P. Fruzzetti, A. Palazoğlu, and K. A. McDonald, "Nonlinear model predictive control using Hammerstein models," Journal of Process Control, vol. 7, no. 1, pp. 31-41, 1997.

[10] S. Nugroho, Y. Y. Nazaruddin, and H. A. Tjokronegoro, "Nonlinear identification of aqueous ammonia binary distillation column based on simple Hammerstein model," in Proceedings of the 5th Asian Control Conference, pp. 118-123, Melbourne, Australia, July 2004.

[11] K. S. Narendra and P. G. Gallman, "An iterative method for the identification of nonlinear systems using a Hammerstein model," IEEE Transactions on Automatic Control, vol. 11, no. 3, pp. 546-550, 1966.

[12] S. Lakshminarayanan, S. L. Shah, and K. Nandakumar, "Identification of Hammerstein models using multivariate statistical tools," Chemical Engineering Science, vol. 50, no. 22, pp. 35993613, 1995.

[13] H. Al-Duwaish and M. N. Karim, "A new method for the identification of Hammerstein model," Automatica, vol. 33, no. 10, pp. 1871-1875, 1997.

[14] E.-W. Bai, "An optimal two-stage identification algorithm for Hammerstein-Wiener nonlinear systems," Automatica, vol. 34, no. 3, pp. 333-338, 1998.

[15] E.-W. Bai, "A blind approach to the Hammerstein-Wiener model identification," Automatica, vol. 38, no. 6, pp. 967-979, 2002. 
[16] F. Ding and T. Chen, "Identification of Hammerstein nonlinear ARMAX systems," Automatica, vol. 41, no. 9, pp. 1479-1489, 2005.

[17] S. I. Biagiola and J. L. Figueroa, "Wiener and Hammerstein uncertain models identification," Mathematics and Computers in Simulation, vol. 79, no. 11, pp. 3296-3313, 2009.

[18] S. I. Biagiola and J. L. Figueroa, "Identification of uncertain MIMO Wiener and Hammerstein models," Computers and Chemical Engineering, vol. 35, no. 12, pp. 2867-2875, 2011.

[19] J. M. Smith, H. C. Van Ness, and M. M. Abbott, Introduction to Chemical Engineering Thermodynamics, McGraw-Hill, New York, NY, USA, 7th edition, 2005.

[20] K. Ramesh, N. Aziz, S. R. Abd Shukor, and M. Ramasamy, "Dynamic rate-based and equilibrium model approaches for continuous tray distillation column," Journal of Applied Science Research, vol. 3, no. 12, pp. 2030-2041, 2007.

[21] L. Ljung, System Identification: Theory for the User, Prentice Hall, Upper Saddle River, NJ, USA, 2nd edition, 1999. 

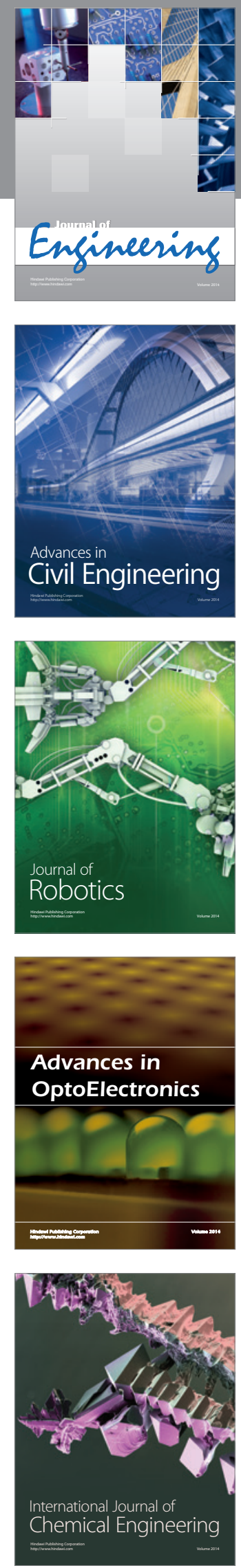

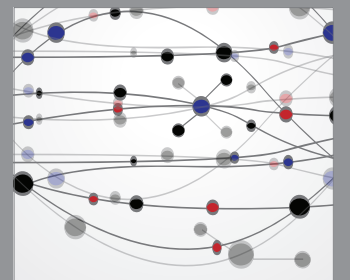

The Scientific World Journal
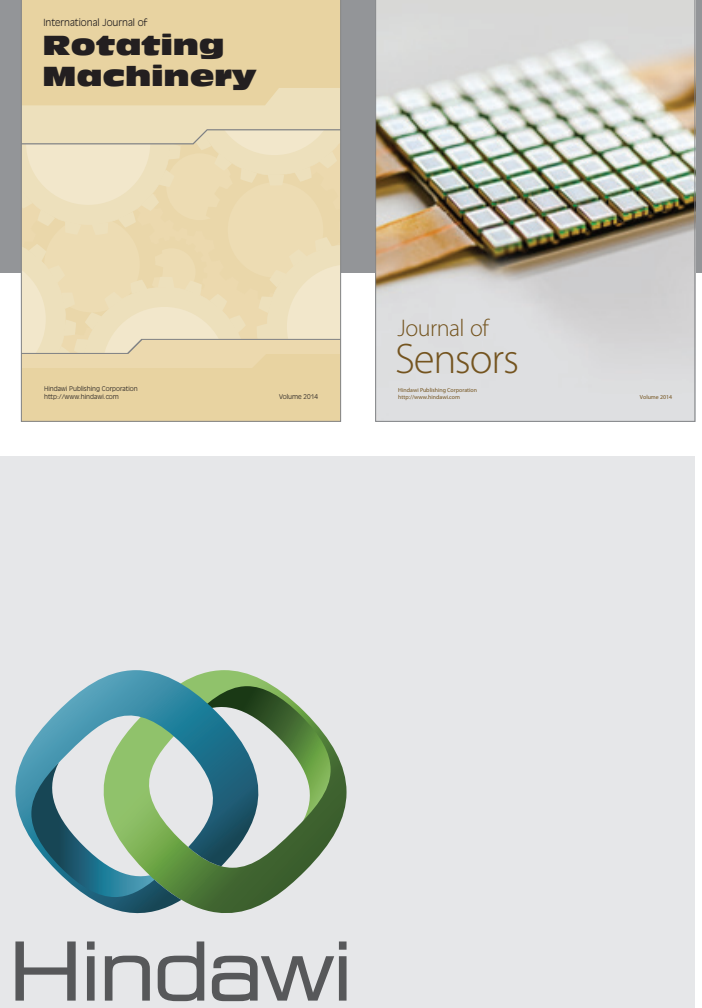

Submit your manuscripts at http://www.hindawi.com
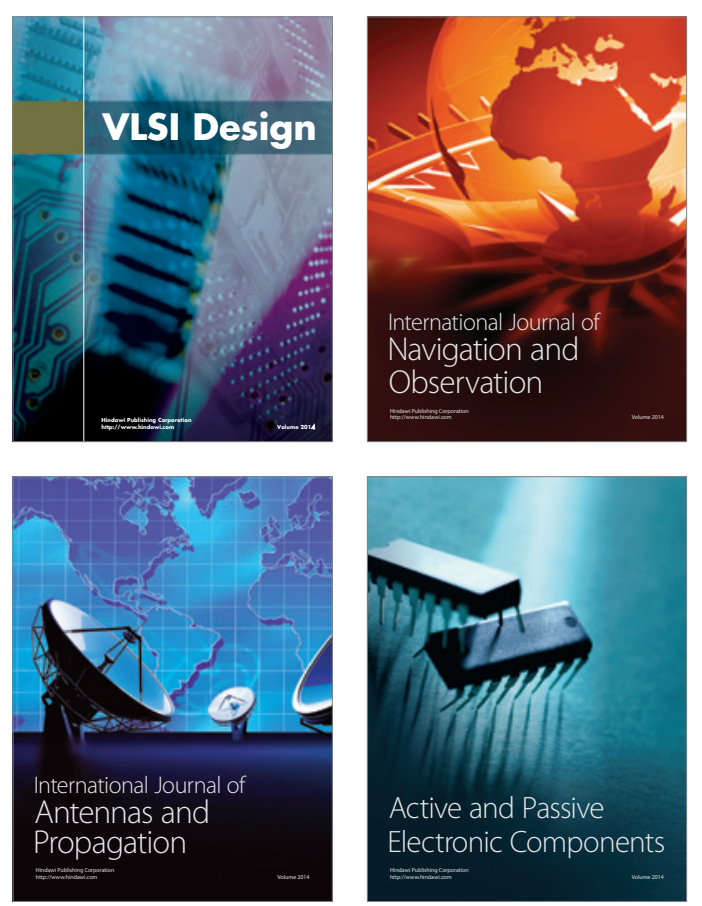
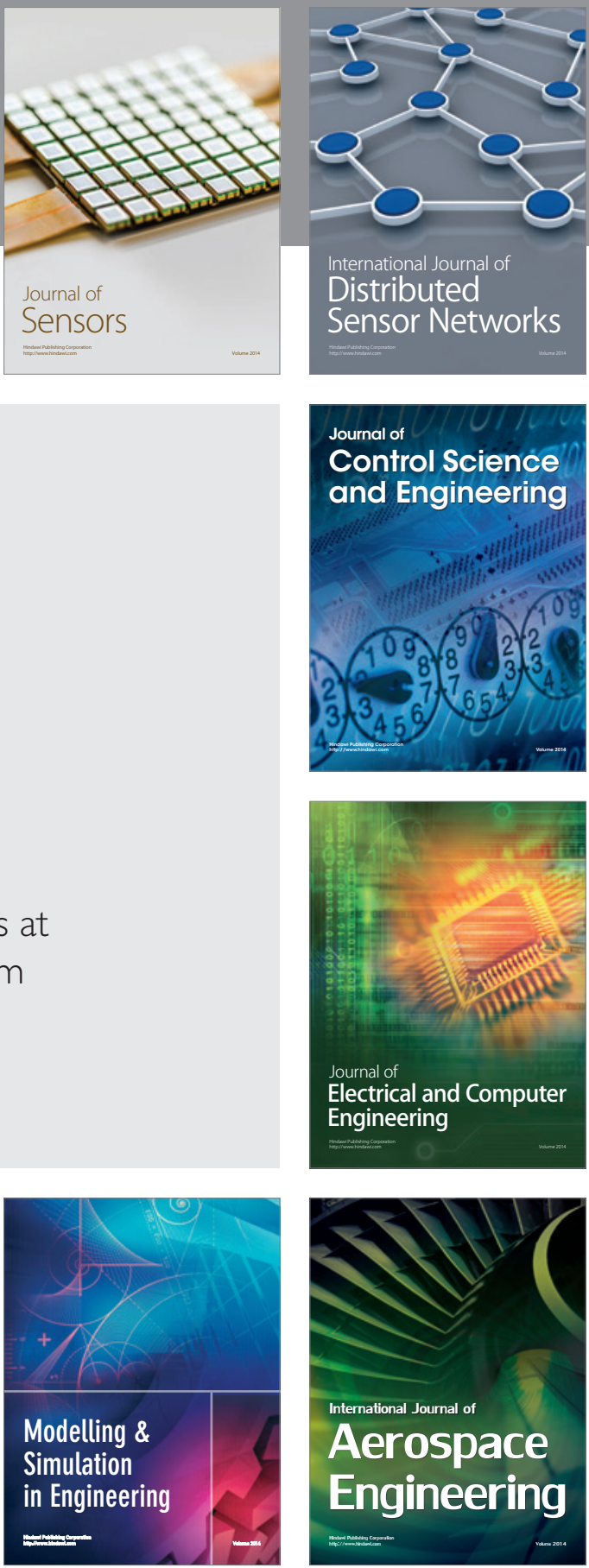

Journal of

Control Science

and Engineering
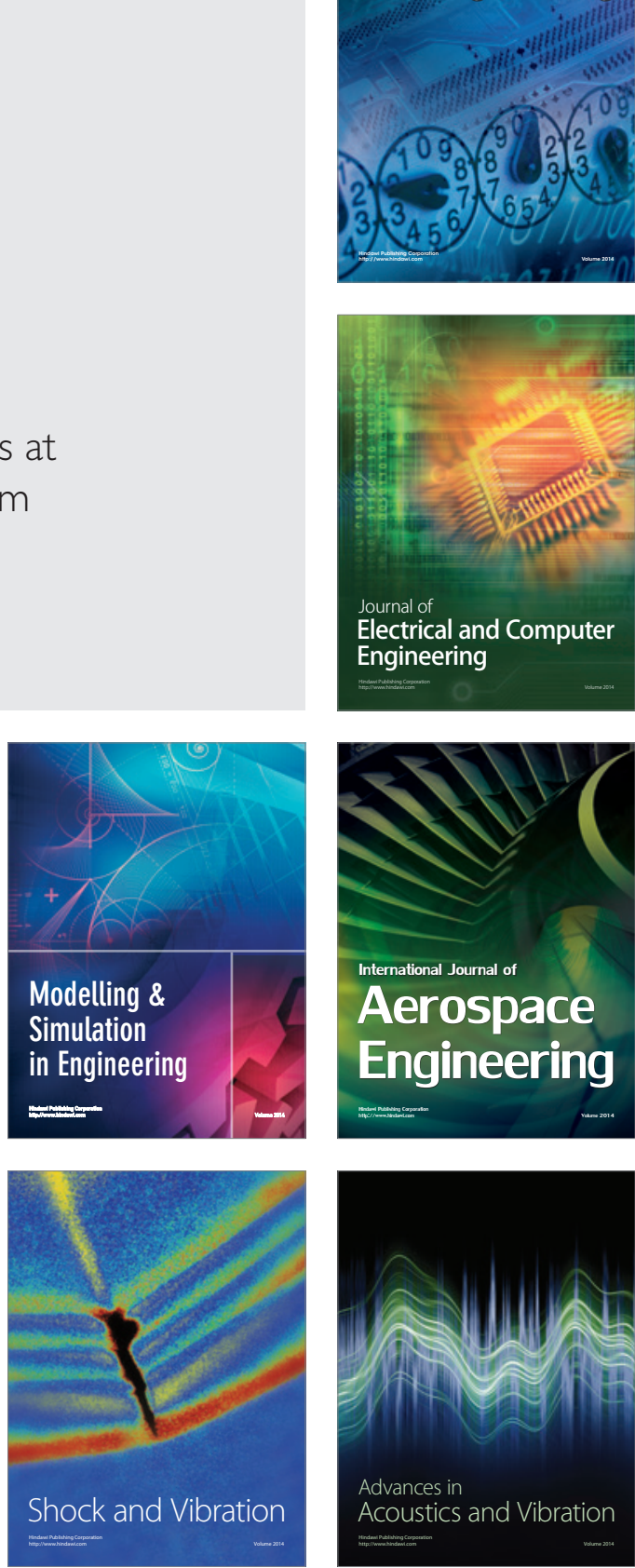